\title{
Elemental mercury intoxication in 7 patients admitted to a pediatric rheumatology clinic
}

\author{
Ayşenur Paç Kısaarslan¹, Betül Sözeri², Funda Baştuğ ${ }^{3}$, Zübeyde Gündüz ${ }^{4}$, Sibel Yel ${ }^{5}$, \\ Hülya Nalçacıoğlu³ ${ }^{3}$ Nihal Şahinn ${ }^{4}$, Sümeyra Özdemir Çiçek ${ }^{4}$, Hakan Poyrazoğlư \\ Ruhan Düşünsel ${ }^{4}$ \\ Departments of Pediatric ${ }^{1}$ Rheumatology and ${ }^{3}$ Nephrology, Health Sciences University Kayseri Education and Research \\ Hospital, Kayseri; ${ }^{2}$ Department of Pediatric Rheumatology, Health Sciences University, Umraniye Education and Research \\ Hospital; Departments of Pediatric ${ }^{4}$ Rheumatology and ${ }^{5}$ Nephrology, Erciyes University Faculty of Medicine, Kayseri, \\ Turkey.E-mail: aysenurkisaarslan@hotmail.com
}

Received: 9th May 2018, Revised: 16th September 2018, Accepted: 23rd September 2018

SUMMARY: Paç Kısaarslan A, Sözeri B, Baştuğ F, Gündüz Z, Yel S, Nalçacıŏlu H, Şahin N, Özdemir Çiçek S, Poyrazoğlu H, Düşünsel R. Elemental mercury intoxication in 7 patients admitted to a pediatric rheumatology clinic. Turk J Pediatr 2019; 61: 786-790.

Mercury $(\mathrm{Hg})$ is a toxic heavy metal that can be classified into three groups; organic (methyl), inorganic (mercuric), and elemental (metallic) mercury $\left(\mathrm{Hg}^{0}\right)$. Mercury intoxication occurs mostly with the elemental form which can potentially damage the function of any organ, or any subcellular structure. The target organ of mercury is the brain, but peripheral nerve function, renal function, immune function, endocrine and muscle function, and several types of dermatitis have been described. We present 7 patients admitted to a pediatric rheumatology clinic with severe extremity pain. One of the patients had acrodynia, two of them had hypertension, two of them had tubulopathy, and three of them had neuropathy. The treatments were Dimercaptosuccinic acid and metalcaptase. In this report, we emphasize that mercury intoxication should be kept in mind with unexplained extremity pain. Timely diagnosis and treatment may prevent severe morbidity and mortality.

Key words: mercury, intoxication, pain.

Mercury (Hg) is a toxic heavy metal that can be classified into three groups; organic (methyl), inorganic (mercuric), and elemental (metallic) mercury $\left(\mathrm{Hg}^{0}\right) .{ }^{1} \quad$ Exposure to elemental mercury stems from industrial fossil fuel emissions, topical medicines, cathartics, dental amalgams, thermometers, sphygmomanometers, barometers, incandescent lights, batteries, medical waste incineration, and $\mathrm{Hg}$-based substances used in ritualistic practices. $^{2}$ Elemental $\mathrm{Hg}$ intoxication in children may result from: inhalation of $\mathrm{Hg}^{0}$ vapor, exposure to mercury dust and powder, exposure to latex paint containing $\mathrm{Hg}^{0}$ based fungicide and accidental ingestion of mercury from instruments, such as thermometers, and dental amalgams. ${ }^{2-4}$ It can be absorbed through the skin or through inhalation of $\mathrm{Hg}^{0}$ vapor. ${ }^{3,4}$
Below we present 7 patients who were admitted to two different rheumatology clinics (Table I). Informed consent form was received from the families.

\section{Case 1}

A 14-year-old boy was admitted with increasingly severe back and extremity pain, weight loss and weakness for two months. Patient appeared ill, and showed Gower's sign on physical examination. The laboratory tests conducted for etiology-complete blood count, blood smear, acute phase reactants (APR), biochemistry, antinuclear anticor (ANA), HLA-B27, viral and bacterial serology, direct radiographies, muscle magnetic resonance imaging (MRI) and bone scintigraphy were 


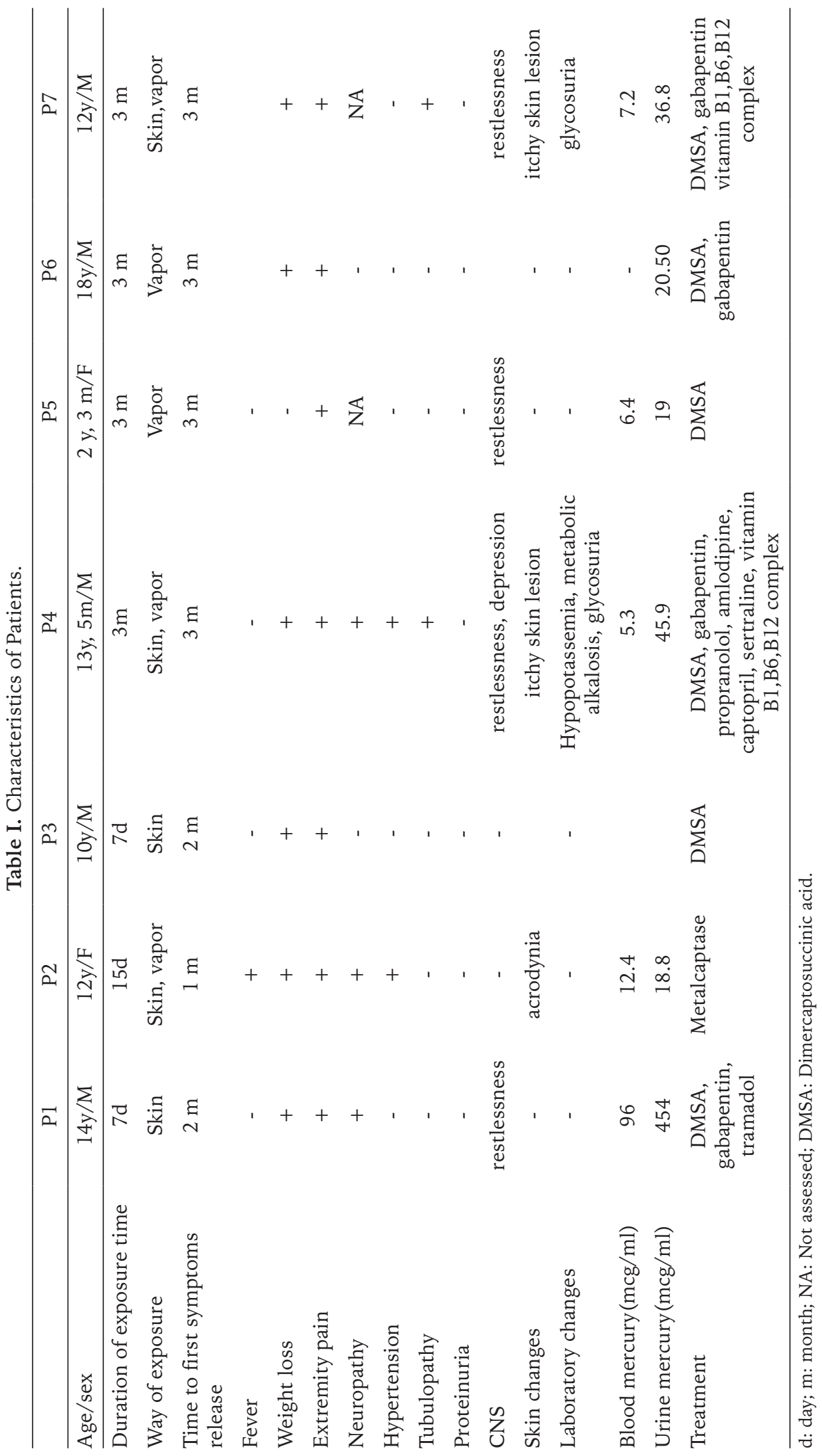


all normal. Mild neurogenic involvement was detected on L2-S1 on electromyography (EMG). We were informed that the patient had played with a mercury bottle on a construction site two months before his complaints began. Urine and blood mercury levels were detected as significantly high. Treatment with Dimercaptosuccinic acid (DMSA) was initiated. The treatment was repeated after one month because the patient's complaints had not reduced. His complaints reduced progressively within 3 months.

\section{Case 2}

A 12-year-old female patient was referred for evaluation of fever, abdominal, extremity and back pain, acrodynia, and hypertension. The preliminary diagnosis was polyartheritis nodosa. The complete blood count, blood smear, APR, ANA, anti-neutrophilic cytoplasmic autoanibody (ANCAs), C3,C4, anti-dsDNA, urinary examination, renal doppler, and MR angiography were detected as normal. Mild neurogenic involvement was detected. Hypertension was under control with two antihypertensive drugs. Urine and blood mercury levels were detected as high. We were informed that she had played with mercury in her school lab one month before her complaints began. Metalcaptase treatment was started. Abdominal pain and acrodynia resolved within 10 days, hypertension resolved within 2 months, extremity pain resolved within 4 months.

\section{Case 3}

A 10-year-old boy was admitted with severe extremity pain for 15 days, weight loss and weakness. Physical examination was normal. Laboratory tests conducted for etiologycomplete blood count, blood smear, APR, biochemistry, ANA, HLA-B27, viral and bacterial serology, direct radiographies and bone scintigraphy- were all normal. Urine and blood mercury levels were detected as high. We were informed that he played with mercury in his school lab 2 months before his complaints began. The patient was treated with DMSA which reduced his complaints within 3 months.

\section{Case 4}

A 13-year-old boy was admitted with severe extremity pain for 30 days, weight loss and weakness. Physical examination showed hypertension and an itchy skin lesion (Fig. 1 ). Laboratory tests conducted for etiologycomplete blood count, blood smear, APR, biochemistry, ANA, HLA-B27, viral and bacterial serology, direct radiographies and bone scintigraphy- were all normal. Tubulopathy was determined. Urine mercury levels were detected as high. We were informed that he played with mercury in his school lab 3 months before his complaints began. The patient was treated with DMSA. Weight loss, the itchy skin lesion and weakness resolved within a month. Hypertension and extremity pain reduced within 3 months.

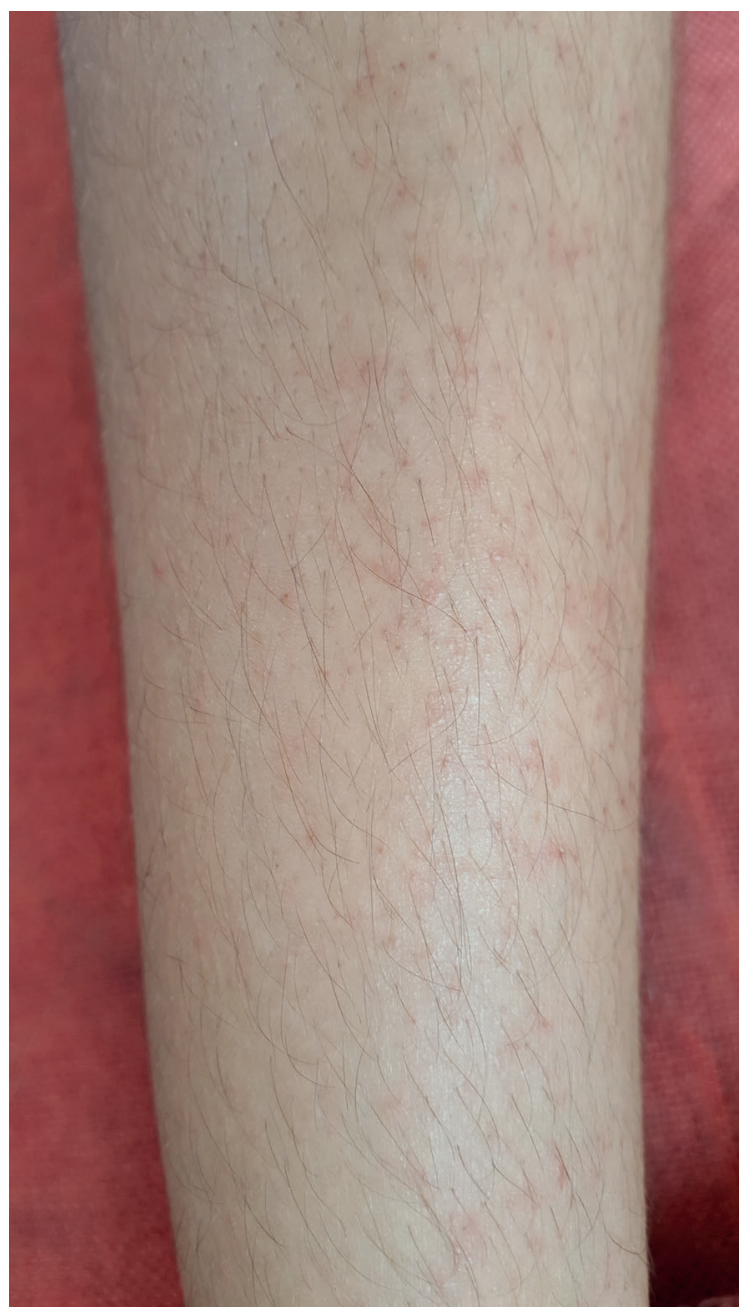

Fig. 1. Skin lesions of patient 4. 


\section{Case 5,6,7}

These patients, whose were siblings of case 4 , were admitted with mild extremity pain. They were referred to us after case 4 was diagnosed. We were informed that Case 4 brought the mercury home, spread it over the carpet, and tried to clean it with a vacuum cleaner. Urine mercury levels were detected as high. These patients were treated with DMSA, and their complaints reduced within 2 months.

\section{Discussion}

There has been a significant increase in mercury poisoning cases since 2000 and most of them $(88.5 \%)$ are due to elemental mercury exposure in school-age children. ${ }^{3}$ This age group children are often attracted to elemental mercury because of its unique physical properties, including silver appearance, density, and tendency to form beads. ${ }^{5,6}$

Inhalation of $\mathrm{Hg}^{0}$ vapors in concentrations greater than $0.05 \mathrm{mg} / \mathrm{m}^{3}$ for significant periods is considered unsafe and the minimum risk level from chronic $\mathrm{Hg}^{0}$ inhalation is 0.3 mikrogram $/ \mathrm{m}^{3}{ }^{2}$ More than $80 \%$ of inhaled $\mathrm{Hg}^{0}$ vapor is absorbed by the lungs. Elemental $\mathrm{Hg}$ diffuses across the membranes of the alveolar sacs and enters the blood to bind with red blood cells in body tissues where it oxidizes to form mercuric ions and binds with the sulfhydryl groups. ${ }^{2}$

Oxidized $\mathrm{Hg}^{0}$ is accumulated in the brain, liver, and cortex of the kidneys. The biotransformation of highly lipid soluble $\mathrm{Hg}$ vapor to mercuric $\mathrm{Hg}$ in the brain may lead to an accumulation of $\mathrm{Hg}^{2+}$ in the cortex and cerebellum, producing impairment of the CNS. The half-life of inhaled $\mathrm{Hg}^{0}$ is 60 days (range 31-100 days), with most being eliminated through urine and fecal excretion. A small amount of absorbed $\mathrm{Hg}^{0}$ is eliminated through exhalation, sweat, and saliva. ${ }^{2}$

Exposure to toxic $\mathrm{Hg}^{0}$ vapors may be acute or chronic. Both acute and chronic $\mathrm{Hg}^{0}$ exposure may induce a broad sequelae of reactions or symptoms, including cough, dyspnea, fever, tremors, malaise, axonal sensorimotor polyneuropathy, gingivitis, delusions, hallucinations, and mercurial erethism, a syndrome that includes excitability, loss of memory, insomnia, extreme shyness, and neurocognitive disorders. ${ }^{3}$

Our patients were exposed to mercury through skin and inhalation. The most common reason for admission to rheumatology clinic was severe and constant extremity pain. All of the patients were irritable and anxious. Celebi et al. $^{7}$ reported that five patients had severe extremity pain related to neuropathy. Beck ${ }^{8}$ reported that sibling patients with severe leg pain, and osteoporotic bones, and sclerotic bands on methaphisis at affected bones. Our patients did not have these pathologic findings on the bones. We assume that the pain is related to neuropathy. We assessed EMG on 3 patients, and detected sensorineural neuropathic findings. Another common clinical finding of our patients was fatigue and weight loss. For this reason malignancy was eliminated by performing blood smear, thorax, abdomen and bone imaging of the patients. Diagnosing patients 1 and 3, who only had extremity pain, took longer. Patient 2 had acrodynia, 2 and 4 had hypertension, 4 and 7 had tubulopathy. These additional findings together with severe extremity pain made diagnosis easier.

Mercury intoxication should be kept in mind with unexplained extremity pain and additional signs of hypertension, weight loss, tubulopathy, anxiety, and weakness. Timely diagnosis and treatment may prevent severe morbidity and mortality.

\section{REFERENCES}

1. Goldman LR, Shannon MW; American Academy of Pediatrics: Committee on Environmental Health. Technical report: mercury in the environment: implications for pediatricians. Pediatrics 2001; 108: 197-205.

2. Counter SA, Buchanan LH. Mercury exposure in children: a review. Toxicol Appl Pharmacol 2004; 198: 209-230.

3. Akyildiz B, Kondolot M, Kurtoğlu S, Konuşkan B. Case series of mercury toxicity among children in a hot, closed environment. Pediatr Emerg Care 2012; 28: 254-258.

4. Carman KB, Tutkun E, Yilmaz H, et al. Acute mercury poisoning among children in two provinces of Turkey. Eur J Pediatr 2013; 172: 821-827. 
5. MacLehose R, Pitt G, Will S, et al. Mercury contamination incident. J Public Health Med 2001; 23: $18-22$

6. Bose-O'Reilly S, McCarty KM, Steckling N, Lettmeier B. Mercury exposure and children's health. Curr Probl Pediatr Adolesc Health Care 2010; 40: 186-215.
7. Celebi N, Canbay O, Aycan IO, Sahin A, Aypar U. Mercury intoxication and neuropathic pain. Paediatr Anaesth 2008; 18: 440-442.

8. Beck C, Krafchik B, Traubici J, Jacobson S. Mercury intoxication: It still exists. Pediatr Dermatol 2004; 21: 254-259. 